\title{
Youth Access to Public Space during COVID- 9 Pandemic in Hanoi, Vietnam. A Descriptive Study
}

Pham Quynh Huong

Center Research for Migration, Environment, and Social Development (CMESD), Vietnam phamquynhhuong2@gmail.com

\section{Phan Song Thuong, Luong Thuy Duong}

Vietnam Academy of Social and Sciences, Institute of Regional Sustainable Development, Vietnam thuongthuong266@gmail.com | duongjuly@gmail.com

Nguyen Xuan An

The Vietnam National Institute of Educational Sciences, Vietnam

nguyenxuanan89@gmail.com

\begin{abstract}
Vietnam is considered to overcome COVID-19 pandemic rather successfully by applying strict measures to prevent transmission, including quarantine and social distancing. It has created impacts on youth access to public space. This is a case study on young people in Hanoi, Vietnam based on the combination of an online survey with 325 respondents and 15 in-depth interviews. The study focuses on reviewing the relations between knowledge of COVID-19 with attitudes toward pandemic control and access to public spaces among youth in order to learn about factors that may influence social distancing and their accessibility to public space.
\end{abstract}

Keywords: hyperlocal social networks, social cohesion, digital public space, community resilience, COVID-I 9

* This article includes research and statistics updated to March 202I.

To cite this article:

Hương, P., Thuong, P., Duong, L., An, N. (2020). Youth Access to Public Space during COVID-19 Pandemic in Hanoi, Vietnam. A Descriptive Study, The Journal of Public Space, 5(3), I3 I-I46, DOI 10.3289I/jps.v5i3.1369

This article has been double blind peer reviewed and accepted for publication in The Journal of Public Space. (c) (1) This work is licensed under a Creative Commons Attribution - Non Commercial 4.0 International License https://creativecommons.org/licenses/by-nc/4.0/ 


\section{Background}

Vietnam is located in Southeast Asia with 96 million populations and shares the northern border with China, which had the first COVID-19 outbreak in the world. Up until 03/202I, Vietnam had suffered from the third phase of the Covid-19 pandemic. By March 6th 202I, there had been 2510 positive cases to SARS-COV-2 reported in Vietnam, including 542 cases being treated, 1920 recovered cases, and 35 deaths.

The first wave of Covid-1 9 pandemic - Study period

Our research was conducted in April 2020 when the first phase of COVID-19 occurred with complicated developments, leading to a 15-nationwide social distancing. By April 24th 2020, Vietnam had reported 270 positive cases, including 45 cases being treated, 225 recovered cases (accounting for 83.3\%), and no deaths ( $\mathrm{MOH}, 2020)$. Among the infected, females account for more than men (54.8\% compared to $45.2 \%)$, with age ranging mainly from 20 to 50 years old. The source of infection is mainly from abroad. Community spreads accounted for only 35.76\% (Vietnam-5F, 2020).

The first wave of Covid-1 9 pandemic and Vietnam's response

During the research process, The Ministry of Health $(\mathrm{MOH})$ divided the pandemic progress in Vietnam into three phases which is briefly described in the paragraphs below.

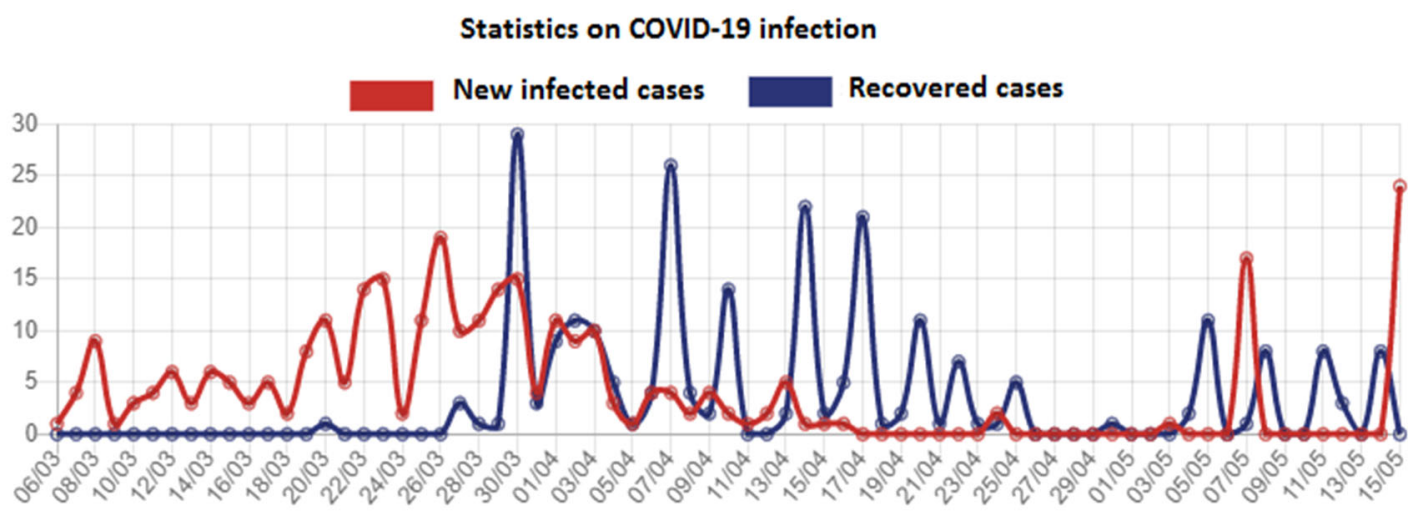

Figure I. Statistics on Covid-19 infection from March 16th 2020 to May I5th 2020.

(Source: MOH, 2020)

Phase I

The first COVID- 19 case was reported in $23^{\text {rd }}$ January 2020. In this phase, 16 persons were infected, treated and already recovered. The infection sources were from people travelling from Wuhan and other countries. There was no transmission case to the community (Le Hiep, 2020). In China, the pandemic hotspot, COVID- 19 started to spread out significantly. The pandemic was transmitted quickly to neighbouring countries (VNA 2020).

As long as the first case in Vietnam was confirm, the government has applied the most stringent preventive measures to minimize contagion. After the country declared COVID-19 as a nationwide epidemic (on February, $I^{\text {st }} 2020$ ), actions were immediately taken. Body temperature control was done to all passengers from China and all 
suspected cases were quarantined. Students throughout the country were not allowed to go to school, and thus, had to stay at home. The whole Son Loi infection commune was confined $(\mathrm{MOH}, 2020)$.

\section{Phase 2}

From $6^{\text {th }}$ March, infection cases mainly came from Vietnamese people travelling back from Europe and the United States. The first cases of community infection were also confirmed. There were two epidemic clusters in Hanoi and Binh Thuan Province. As on $19^{\text {th }}$ March Vietnam had 85 cases, of which 69 on treatment and no death. On March, II $^{\text {st }}$ 2020, WHO officially declared COVID-19 as a global pandemic (VNA, 2020). On $17^{\text {th }}$ March, Vietnam temporarily suspended visa grants for entry foreigners. Vietnam Airlines ceased all incoming international flights. From $2 I^{\text {st }}$ March, Vietnam stopped visa grants for all foreigners. All people from abroad entering Vietnam were sent to concentrated quarantine camp in 14 days. Two epidemic clusters were isolated. From 28 March, all crowded-gathering activities were shut down $(\mathrm{MOH}, 2020)$.

\section{Phase 3}

On 20 March, there were some infection cases in community that could not identified infection sources. There were two big epidemic outbreaks at Bach Mai Hospital in Hanoi and Buddha Bar in Ho Chi Minh City. Within a month, the infection cases increased rapidly, but so did the recovered ones. After two weeks of social distancing along with other preventive measures, Vietnam had no new case. After social distancing was relaxed, from $7^{\text {th }}$ May there appeared new cases from abroad (VNA, 2020).

Strongest preventive actions were taken such as limiting gatherings, cluster lockdown, social distancing, and compulsory I4-day quarantine after entry into Vietnam $(\mathrm{MOH}$, 2020; VGP, 2020).

In Vietnam to ease the control and communication, the Ministry of Health encodes the coronavirus infected and suspected people as follows: F0 as a Coronavirus infected person, $\mathrm{FI}$ as a person who has direct contact with F0 had conversation in 15 minutes or more, in a distance of less than 2 metres; who was in the same hotel or on the same flight as the F0. Similarly, F2 is someone who has been in direct contact with FI.

\section{Study objectives and methodologies}

The subject of this study is to research behavioural changes among Hanoi youth in access to public spaces and adaptation to social distancing. This study focuses on reviewing the relations between knowledge of COVID- 19 with attitudes towards pandemic control and access to public spaces. The study also learns about factors that may influence social distancing, including those that encourage access to public space and those that have impacts on the understanding of pandemic-caused risks.

The case study was carried out via an online survey and in-depth interview. An online survey was conducted with a short questionnaire of 12 questions. Face-to-face in-depth interviews with young people living in Hanoi were done by sociologists. The study was carried out during social distancing time in Hanoi (April $20^{\text {th }}$ ) to its end (on May $10^{\text {th }}$ ). There was total of 325 online respondents and 15 in-depth interviews taken. The table I below illustrates characteristics including gender, age, and education of participants of the online survey. Participants consists of more females than males. Most of them are under 30 years old, and graduate education. 
Youth Access to Public Space during COVID-19 Pandemic in Hanoi, Vietnam

Table I. Demographic about online respondents

\begin{tabular}{|c|c|c|}
\hline & Frequency & Percentage \\
\hline \multicolumn{3}{|l|}{ Gender } \\
\hline Male & $|5|$ & 46.5 \\
\hline Female & 174 & 53.5 \\
\hline \multicolumn{3}{|l|}{ Age } \\
\hline Under 20 & 99 & 30.5 \\
\hline From 20 to 30 & 161 & 49.5 \\
\hline Above 30 & 65 & 20.0 \\
\hline \multicolumn{3}{|l|}{ Education } \\
\hline High school & 22 & 6.8 \\
\hline $\begin{array}{l}\text { Undergraduate, } \\
\text { Graduate }\end{array}$ & 303 & 93.2 \\
\hline
\end{tabular}

\section{Study findings}

I. Knowledge of young people about COVID-19

During COVID-19 time, "social quarantine" and "social distancing" were two measures successfully applied to improve efficiency in pandemic control in Vietnam. Most respondents had an explicit distinction between these two terms. According to their understanding, social distancing meant limiting contact with people within a short distance while social quarantine meant staying at home. The interests in learning about social quarantine and distancing were seen vividly when the social distancing order was implemented throughout the nation. Specifically, the sudden increase in number of searches for these two keywords on Google/Google Trends is a clear evidence for the people's concern.

Social quarantine was considered necessary, especially at the pandemic peak in Vietnam (the first half of April 2020) while social distancing was more suitable for the after-peak period. Social quarantine and distancing were essential even though they caused negative impacts on the economy and people's lives.

"Social distancing and quarantine are highly necessary because if the pandemic outbreak, it would cause severe consequences and the number of deaths would grow in an unpredictable manner."

(Female, 22 years old) 


\section{Youth attitudes toward COVID- 19 and access to public space}

2.I. The attitude of young people towards COVID-19 epidemic

- Worry about the disease and the spread of the disease.

Many people felt worried about the pandemic outbreak when the $17^{\text {th }}$ case was reported in $7^{\text {th }}$ March 2020. She was the first person found positive for coronavirus on a crowded flight. As a result, all passengers and aircrews on this flight were at risk of being infected, which forced them to be isolated from other people. This created a mass effect in society. People rushed to shops to get supplies.

"Right when the I $7^{\text {th }}$ patient appeared, I felt that the disease was so dangerous and very close to me. No one knows who she/he had contact with, with or without pathogens. Transmission risk is high."

(Male, 29 years old).

Most of respondents in in-depth interviews were afraid of the increased outbreak of the disease, because at the time this research was conducted, the vaccine for this disease was still being studied while the situation in European countries was very complicated.

"Coronavirus is really scary because of its danger and its contagion speed. Moreover, there have not been vaccines for it. In Vietnam, however, there were many people who have been cured but there are also many who tested positive for coronavirus again (twice or 3 times) and struggle to recover completely". (Male, 22 years old, student)

"Before the I 7th patient, I was not afraid because I thought it was just a common flu epidemic. However, when the 17th patient was detected and the disease broke out in Europe were the most worrisome."

(Male, 23 years old, tour guide)

Young people in the research are those whose jobs were in regular contact with other people or working outside, such as doctors, nurses, or tour guides. They are much more afraid of the danger and the spread of COVID-I9.

"As a trainee at Bach Mai Hospital, I regularly use food and drink services at Truong Sinh (I-2 times / day) [Truong Sinh is a service facility in the hospital, and an outbreak] so there is a possibility that I am F2 or F3. However, as soon as it was confirmed that the I7th patient was positive, we were instructed to limit our visits to the clinic and to eat in the room. Until the case of a nurse at the infectious transmission department was positive, we were tested and isolated at home". (Female, 22 years old, student)

"I am at risk of infection because I work as a tour guide and have a lot of contact with foreigners. There are days when I feel tired, so I also worry about being infected."

(Male, 23 years old, tour guide) 
- $\quad$ Believe in the measures to prevent COVID-19 from government Besides, there were others with fewer worries as they believed in pandemic preventive measures by the Government and communities.

"The pandemic is not so worrying if we place our trust in the government disease prevention and control activities and we have senses in pandemic control according to instructions by the Ministry of Health."

(Female, 21 years old).

"The disease has spread and there were people who died because of it so it is right to feel afraid. But we shouldn't be worried much. We have measures to prevent it and if people are conscious, it can be prevented. It depends on humans to let the epidemic spread much or not. If there is one person who is unconscious like without social distancing and social quarantine, the virus will spread from I to I00 people and much more."

(Female, 19 years old, student)

"In my opinion, on a I0-point scale, my fear level of epidemic is only at 5 because I see that Vietnam has been very proactive. Shown through the cases of the I7th patient or the outbreak in Bach Mai hospital, the intervention of the media or the social confusion of people are the reason for this proactiveness. If we are conscious and have good perception in self protection, self-isolation and social distancing as directed by the Prime Minister, there is no need to worry uncontrollably."

(Female, 22 years old, student)

2.2. The psychological effects that young people experience when implementing social distancing and social quarantine.

In the context of the rising epidemic and isolation measures applied, fear and anxiety have become common. At the same time, the social distancing and implemented limits have created tremendous pressure on people, including young people. Many people have experienced different psychological stages from imbalance to adaptation. The general feelings among youth were uneasiness and discomfort when they had to stay at home and limit physical contact with colleges and friends. Youths with high outdoor activity habits felt more difficult when staying inside their homes.

"I felt sad, bored and there was nothing left for me to do because I used to work outdoors. At home, sometimes I felt stressed and stifling." (Male, 23 years old).

"When I practiced social distancing and stayed at home, at first, I feel frustrated and bored. It is boring because I had to repeat everything day by day."

(Female, 21 years old, students)

"There was a bit of a break due to not interacting with friends, not having entertainment activities and doing sports."

(Male, 19 years old, student) 
"I think that, when I was at home for 2 weeks for social quarantine, I was very uncomfortable because my house is small. I do not have enough space to exercise on my own.

Being in the room too much and using the internet for entertainment for too long also made me feel uncomfortable and tired in the morning which made it difficult to sleep at night."

(Female, 22 years old, student)

\subsection{The importance of public space to the young folks.}

Research about Public space in the Hanoi area of Doan The Trung and colleagues (2018) reported that teenagers and young adults actively came to public spaces and considered these being their regular activities. Spaces namely sidewalks, parks, gardens or walking streets were popular locations where the youngsters often visit during the weekends or their free time. Apart from this, serving the needs of improving health or playing sports such as football yards and other spaces were also preferred by young people.

Young people desire for quarantine to end of the quarantine also reflects their anxiety and dissatisfaction as well as the importance of public space. Social quarantine and social distancing have urged young people to temporarily give up their habit of accessing public spaces. As a result, when people were asked about their willing after social quarantine and social distancing, many commented that they would return to public spaces as a routine. The table below illustrates the most impressive memory of youth in Hanoi about public spaces (Table 2). These places would be their first places they would like to visit right after the quarantine end. During the social quarantine, most youngsters missed going to the locations for communication and urban services $(47,4 \%)$, followed by lovely hubs of Hanoi $(35,9 \%)$ and public spaces with Hanoi's identity. This means that public spaces are not just the areas daily activities, but rather reflect the lifestyle of city's residents, their strong connection to the city and carry the identity of the capital.

Table 2. Most impressive memory about public space. Source: Survey 2020.

\begin{tabular}{l|l} 
Most impressive memory about public space & $\begin{array}{l}\text { \% within the total } \\
\text { surveyed people }\end{array}$ \\
\hline Place for communication and urban services & 47.4 \\
\hline Lovely hubs of Hanoi & 35.9 \\
\hline Public space with Hanoi's identity & 37.8 \\
\hline Places for study and work & 8.3 \\
\hline Exercises, sports, culture & 5.8 \\
\hline Relating to Covid-19 & 6.4
\end{tabular}

Many people had a strong attachment to public spaces. Most of them prioritized public spaces as the foremost location to come after the quarantine (Table 3) with public space including areas with services $(31,52 \%)$ school, hospitals and public constructions $(20,61 \%)$ as well as official public spaces (19,39\%). 
Youth Access to Public Space during COVID-19 Pandemic in Hanoi, Vietnam

Table 3. Places that are looked forward to being visited after the quarantine. Source: Survey 2020.

\begin{tabular}{l|l} 
Places that are looked forward to being visited after the quarantine & Percentage (\%) \\
\hline Official public spaces & 19.39 \\
\hline Areas with service (cafes, restaurants, vendors) & 31.52 \\
\hline Unconstructed spaces & 25.45 \\
\hline Schools, hospitals and public constructions & 20.61 \\
\hline Stay at home & 3.03
\end{tabular}

Many people hoped that by the end of the quarantine, they could return to public spaces and experienced their activities here like before (Figure 2). Young people still wished to access public spaces for social activities (60.6\%) and entertainment (29.7\%). Thus, accessing public space was an essential need and an ongoing expectation of many.

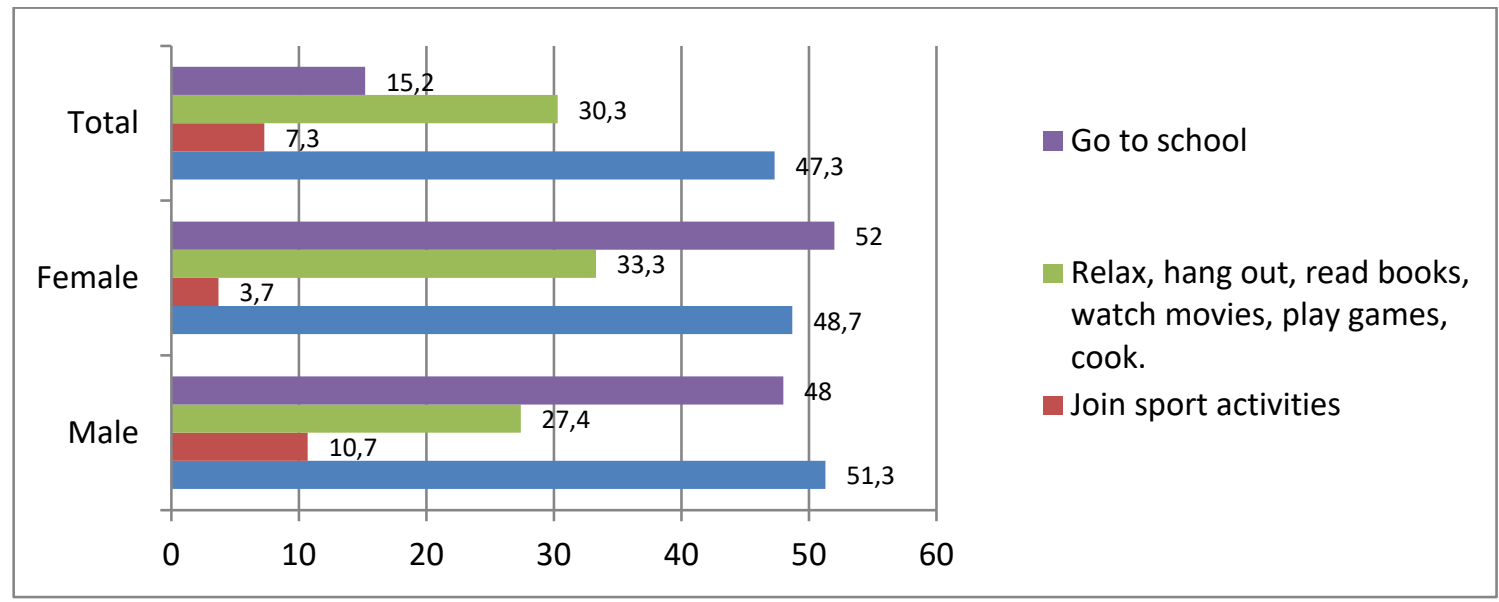

Figure 2. Wished activities in public spaces of young people after the quarantine. Sources: Survey 2020

When social distancing was compulsory, everyone missed public spaces with many activities. Right in social distancing time, people missed and had more understanding of the value of public spaces.

"I love the feeling of being with friends and chatting while drinking tea or eating meals at familiar sidewalk restaurants" (Female, 22 years old). "I miss Football yards, gyms for sport activities, and cafes to communicate with others that are basic activities in daily life."

(Male, 24 years old).

To many people, public spaces are their favourite places where they can relax and enjoy the moment with their friends and families. 
"I prefer enjoying my favorite drink in a tranquil cafe alone, which makes me focus on my work and spares me a comfortable space. Driving around West Lake with my friends is also a good choice since the sight and the atmosphere here ease my mood.

(Female, 22 years old).

"I love to have a cup of coffee or tea after having breakfast, or gossip with my close friends about our quarantine and difficulties".

(Male, 23 years old)

Many people, with various intentions, have looked forward to the end of the quarantine so that they can be back to public spaces.

"I will go to West Lake first to breathe the air because West Lake is a very airy and comfortable place that is easy to relieve pressure and bring comfort to me." (Female, 21 years old). "I would go to the restaurants first since my appetite has obsessed and discomforted me during the quarantine. I want to return to my daily routine via my hobbies as soon as possible"

(Male, 23 years old).

\section{Behavioural changes among young people in COVID- 9 social distancing}

\section{I. Accessing and using public spaces before Covid-19 pandemic}

Public spaces are perceived differently among respondents. In this research it might include parks, big squares, services space, cafeteria or other useful spaces like grounds, empty spaces, flyovers, sidewalks, temples, pagodas, etc.

Public spaces were utmost necessary and closely attached to the life of Hanoi youth. Before the pandemic, Hanoi young people used to visit public spaces. The very frequent and frequent levels were respectively $31.7 \%$ and $39.1 \%$ (Figure 3 ).

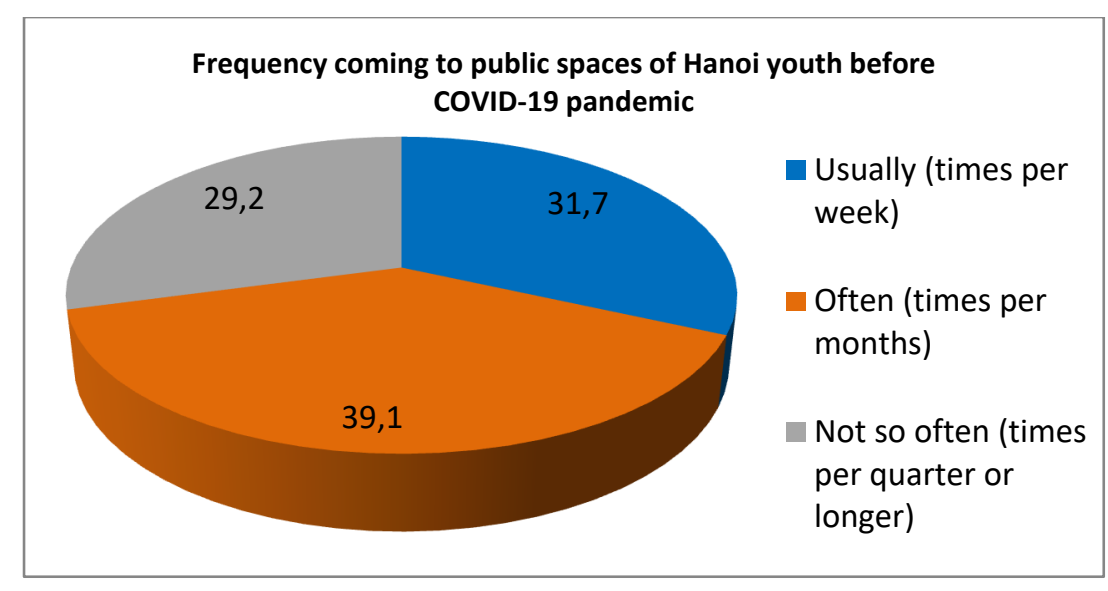

Figure 3. Frequency coming to public space of Hanoi youth before Covid-19 pandemic Source: Survey 2020

Their main needs when accessing public spaces included entertainment, relaxation (79.4\%), meeting, eating and sharing information with others $(52.0 \%)$, having chats with lovers, friends, and relatives (50.8\%) (Figure 4). 
Youth Access to Public Space during COVID-19 Pandemic in Hanoi, Vietnam

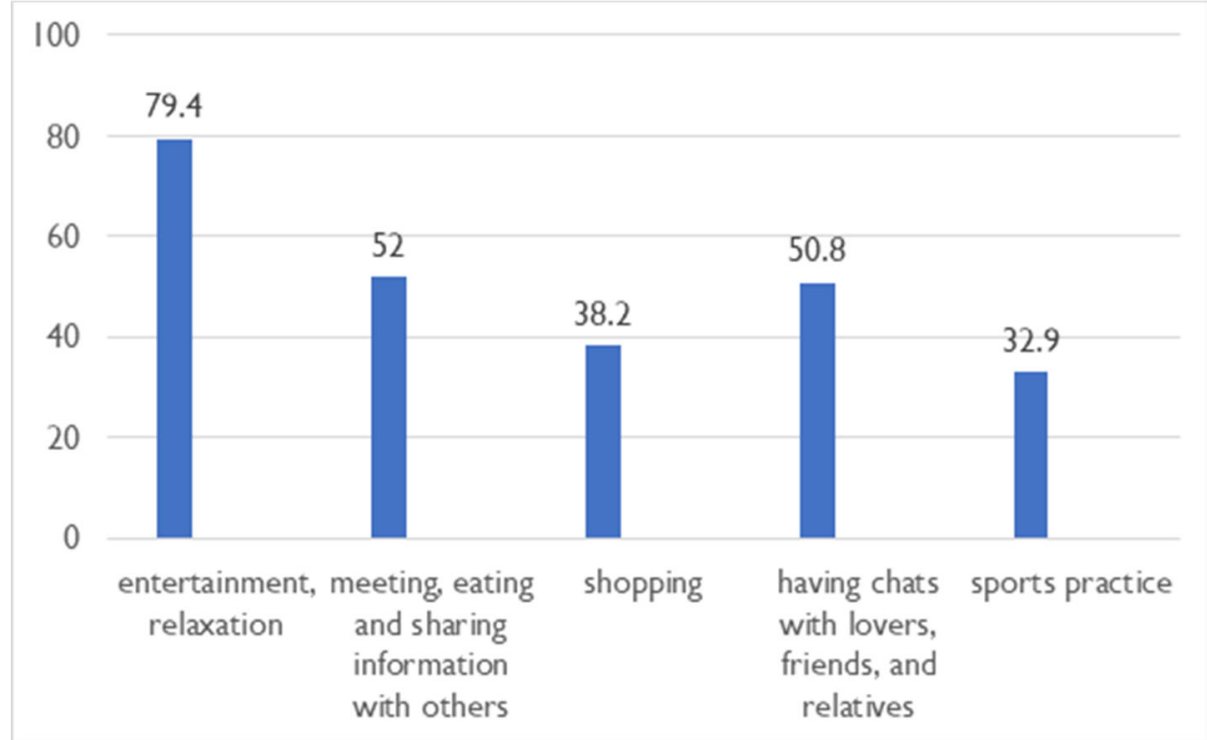

Figure 4. Activities at public spaces by Hanoi Youths before Covid-19 pandemic. Source: Survey 2020

Public spaces were places for young people to have social activities with friends, coworkers and neighbours (83.2\%), or with family members (48.8\%) (Table 4). Women were often with their relatives and friends ( $60.5 \%$ and $53.0 \%$ respectively), while most respondents visiting public space alone were men $(81,8 \%)$. These results depict the importance of public space to Hanoi's young population (Table 4 and Figure 5). Public spaces are where they spend their time chatting and relaxing with their friends, families and colleagues.

Table 4. With whom Hanoi youth go to public spaces. Source: Survey 2020

\begin{tabular}{l|c|c|c} 
Person/ people to access to public space with & \% of total & \multicolumn{2}{|c}{ \% within gender } \\
\cline { 3 - 4 } & & Male & Female \\
\hline Families and relations & 48.8 & 39.5 & 60.5 \\
\hline Friends, colleagues, neighbours & 83.2 & 47.0 & 53.0 \\
\hline Alone & 3.4 & 81.8 & 18.2
\end{tabular}

3.2. Adaptation activities in the time of social distancing

During the social distancing period, people were put under psychological pressure, especially those who were used to hanging out at public spaces. Concurrently, there were also changes in their daily lives and behaviours to adapt with the new situation. 


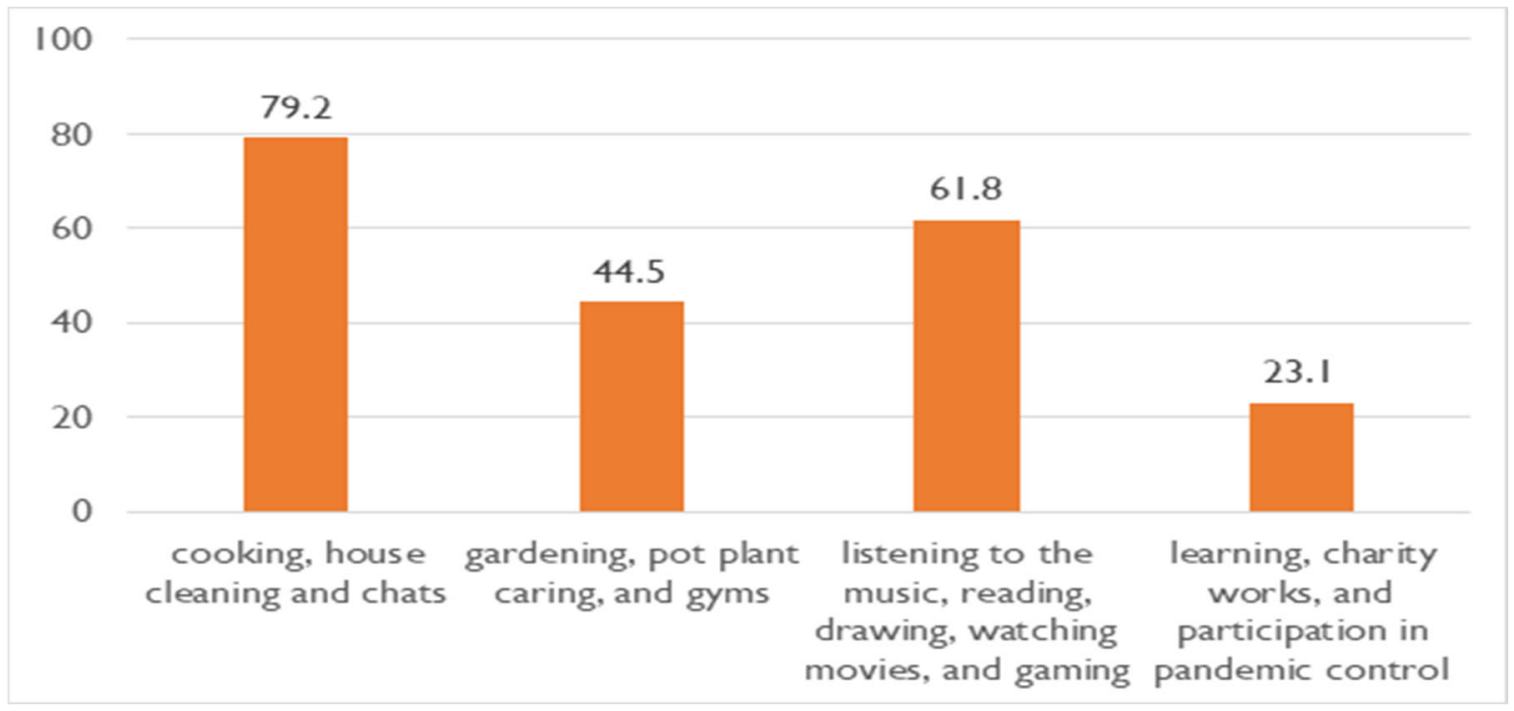

Figure 5. Adaptation activities of Hanoi youth in the time of social distancing. Source: Survey 2020

According to the online survey, during the social distancing period, people's behaviors changed to adapt (Figure 5). They spent most of their time interacting with family members via activities like cooking, house cleaning and chats (79.2\%). They also had more time for personal entertainment activities like listening to music, reading, drawing, watching movies, and gaming (6I.8\%); physical activities like gardening, pot plant caring, and exercising (44.5\%). About one fourth (1/4) took active social actions like learning, doing charity works, and participating in pandemic control (23.1\%). A very interesting fact is that more female youngsters took their time cooking and chatting with family members than males (Table 5), while men participated in sport activities and other entertainments more than women did.

Table 5. Activities during social distancing. Source: Survey 2020

\begin{tabular}{|c|c|c|c|}
\hline \multirow[t]{2}{*}{ Activities } & \multirow[t]{2}{*}{$\%$ of total } & \multicolumn{2}{|c|}{$\%$ within gender } \\
\hline & & Male & Female \\
\hline Cook, tidy, chat with family members & 43.8 & 56.2 & 79,2 \\
\hline Garden, exercise, play sport & 53.2 & 46.8 & 44,5 \\
\hline Listen to music, read books, draw, watch movies, play games & 58.9 & 41.1 & 61,8 \\
\hline Study and volunteer, support activities preventing Covid-19 & 52.5 & 47.5 & 23,1 \\
\hline
\end{tabular}

While many people struggled to stay at home most of the time, others found solutions. After a period of implementing social distancing and social quarantine, some young people in the survey found a way to adapt to not going out, participating less in community activities and using public spaces. Feelings of boredom and frustration have 
also gradually been replaced by increased feelings of comfort with indoor activities or activities in quiet spaces.

"In order to replace the activities in public spaces which I cannot do, I take time to do what I love like cooking for the family, watching movies, and playing games. In the past, I had more face-to-face talks with friends, now I have less chat with them. Sometimes, I text them to kill time." (Female, 22 years old).

"In the first days, I felt bored and uncomfortable but after that I found comfort. I had more time to study, take care of myself, listen to my inner-self, be moderate and take a suitable diet and physical activities" (Female, 22 years old).

Many found positive aspects of staying at home.

"During social distancing, my family always had reunion meals. Before, I was occupied and had less time to talk with others. During social distancing period, my family members play together. I even have more time to take care for my parents and myself."

(Female, 21 years old).

"I just have a little bit of frustration due to not hanging out with my friends, and not having entertainment outside. I have more favourite activities at home now. I listen to music and watch

films alone. Sometimes, I watch movies with my younger brother, but I mainly watch alone. I also do exercises to maintain my activeness."

(Male, 19 years old, student)

During social distancing period, people's behavioural changes were reflected by taking more moderate living and better care for themselves and their families. Here after are some examples of these behavioural changes:

"I do more physical activities and pay more attention to personal hygiene. Staying at home is also interesting because there is more time to care for my home, play with cuisine and enjoy life."

(Male, 29 years old).

In addition, social distancing changed ways of communication with relatives and friends, working methods, and online learning. Online communication advanced during the COVID-I9 pandemic. "Physical visits to friends are limited so I text and use Facetime instead.

However, such changes in communication are less comfortable, natural and emotional than face-to-face interactions."

(Female, 21 years old).

\section{Discussion \& Conclusion}

- Public space accessing before the COVID-19 pandemic

There are diverse forms of public spaces in Vietnam as a whole and in Hanoi specifically. Hanoi has parks ranging from small to large scales, but sidewalks are noticeable as the most popular kind of public space in this city. Many daily activities of Hanoi residents 
occur there, especially in the area near the city centre. Cafes and street vendors abound alongside the pavements which are students' favourite places. The most frequent activities here include walking, sitting, chatting, relaxing, eating and drinking. (Sanders et al., 2015; Nguyen Quang Minh et al., 2019).

Activities in public spaces are quite various. While there are soft activities namely gossiping, watching other people, studying, doing exercises, and playing sports. Some people prefer more lively ones such as skating, hip-hop and flash-mob dancing (Geertman et al., 2016; Tran, 2015; Pham et al. 2019). Most people come to public spaces for physical and exciting activities. To be more specific, just one third of the total did soft activities, whilst respondents visiting public space for other purposes occupied only a small part (I3\%) (Geertman et al., 20I6). Interests of young people also vary from one to another. Some youngsters are keen on private and tranquil public space with a good light system. There are some that dislike crowded places or public space with many guards. Meanwhile others prefer lively and bustling public spaces. In addition, young people choose public spaces to perform impressive shows or experience new activities that have not been accepted by the authority (Geertman, 2015; Tran, 20I5). The diversity of public spaces together with various activities here have created a unique identity of urban areas which is a part of Vietnamese citizens and the young population's lifestyle.

- Negative impact on mental health and daily lives

The quarantine has a negative impact on many people's mental health and daily lives, especially young adults and teenagers who are used to participating in social activities in public space. Beside concerns about the pandemic, residents also have to suffer from confined, stifling feelings when they stay at home and are not able to be involved in daily habits involving social interactions namely shopping with their friends or families, going for a walk or playing sports. This result is similar to ones of other research. Covid-19 pandemic is responsible for an increase in anxiety and stress of people all over the world (WHO, 2020). According to a study on the impact of the pandemic on every aspect of the society, the pandemic affected the mental health of many social groups, regardless of their classes. To be more specific, their behaviours show signs of frustration, distress and worry more regularly. The more time they spend at home, the more pressure and depression they are put under (Elgimati and colleagues, 2020). A research at the start of 2020 which surveyed students who had to stay at home recorded a high anxiety level among these young people (Wang \& Zhao H, 2020). Another research conducted in February 2020 which aimed at the impact of the COVID pandemic on Chinese citizens reported that most Chinese do not suffer from anxiety or depression (Yenan, 2020). It is also believed that youngsters are negatively affected more easily than their seniors, while women are often more anxious than men. Highly-educated people are notably proved to be more depressed that those who have lower education, and people working in specialized fields are at higher risk of suffering from anxiety and depression than laborers or service workers. As shown from these results, groups of young people who receive higher education are more vulnerable to mental health impacts of COVID-19. Due to this, respondents who are young adults and teenagers of the surveys are looking forward to the end of the social quarantine and the social distancing when they can return to their routines in public spaces. Besides, many people also hope to meet and communicate with their friends again. 
- Positive attitudes towards pandemic prevention.

Despite suffering from mental problems due to the COVID-19, in-home quarantine, and being limited from accessing public space, teenagers and young adults complied the quarantine request with a positive attitude. This can be attributed to several attempts of the government. According to the research of Nguyen T.T.P. (2020) in April 2020, in the circumstance when Vietnam had weak preventive strategies, the state had to consider efficient solutions to "flatten the bend" of the total positive cases. This means that the role of the government in instructing and announcing explicit and public information together with the involvement of social media play a significant part in reinforcing citizens' trust in the government's policies, therefore changing citizens' behaviours regarding pandemic prevention (wear mask, wash their hands, keep distance, health declare). This can explain the faith of young people in this research as well as why they adapt with modifications in behaviours after they were prohibited from accessing public space during the quarantine.

- Social distancing has made many people change their attitudes and behaviours. In Vietnam, several new trends have appeared, especially among young family to reduce stress during the social quarantine. Online groups namely "Hate kitchen, not addicted to home", or "Love kitchen, addicted to house" with up to about tens of thousands of participants are notably a trending phenomenon. These are places where Internet users share their funny moments of cooking, tidying, or feeling relaxed when they do household chores. Besides that, several indoor sports activities are done with the encouragement of gyms and medical staff who upload their exercise instructions on the Internet ${ }^{2}$. It is not to mention voluntary attempts during the COVID-19 period. Many groups have actively supported doctors, families meeting difficulties due to the pandemic ${ }^{3}$, which is considered as an initiative of citizens and young people to balance the COVID-19 life.

Young people participating in this research has adapted several changes in order to deal with the quarantine and distancing due to COVID-19. In the social distancing period, there have been many activities to enhance communication among family members and enable them to have more time for personal activities. Many at-home activities have been created to help people maintain their sense of balance. However, being unable to access public space, many people gain a better understanding of the value of public space in their daily life. Public space remains the top expected destination to visit of everyone after the pandemic ends.

\footnotetext{
' https://laodong.vn/chuyen-nha-minh/suc-hut-cua-hoi-ghet-bep-khong-nghien-nha-dang-gay-bao-mang-xahoi-798498.Ido

${ }^{2}$ https://hellobacsi.com/benh-truyen-nhiem/coronavirus/tap-luyen-the-duc-tai-nha-trong-mua-dich-covid$19 / \#$ gref

${ }^{3}$ http://bvydhue.com.vn/cl01/t/01-917/nhung-tam-long-thien-nguyen-trong-mua-dich-covid-19.html
} 


\section{Acknowledgment}

Our special thanks go to the Project of Transformative Youth Spaces (TRYSPACES) for creating conditions and support for the ideas and activities of the study group. We highly appreciate the ideas suggested by City Space Architecture. We would like to thank Ms. Truong Thi Ly and Ms. Do Thi Ngan for their taking part in conducting indepth interviews.

\section{References}

Doan The Trung, Ta Quynh Hoa, Nguyen Quang Minh, Tran Minh Trung, Nguyen Manh Tri, Chu Ngoc Huyen, Pham Tien Hau (2018) 'Summary report of the public spaces observational survey phase I'. Report of NUCE Team for TRYSPACES Hanoi.

Elgimati, Y., Alrasheed, A. and Mohamed Bashir, A. (2020) 'Effect of a COVID-I9 on Social, Psychological, Economic and Health Conditions in Libya', Journal of Applied Science, Engineering, Technology, and Education. Takalar, Indonesia, 3(2), pp. 160-170. doi: 10.35877/454RI.ascil 36.

Geertman, S. (2015) 'Youth - friendly public space in Hanoi', VIUP Journal of Construction and Planning', No. 74, pp. 35-37.

Geertman Stephanie, Danielle Labbé, Julie-Anne Boudreau, Olivier Jacques (2016) 'YouthDriven Tactics of Public Space Appropriation in Hanoi: The Case of Skateboarding and Parkour', Pacific Affairs, Vol. 89 (3), pp:59I- 6II.

Le Hiep (2020) 'The overview of 3 phases of Covid-19 epidemic in Vietnam', https://thanhnien.vn/thoi-su/toan-canh-3-giai-doan-dich-covid- I9-tai-viet-nam-1207707.html.

Ministry of Health (MOH) (2020) 'Coronavirus Disease (COVID-19) Outbreak in Vietnam', Ministry of Health, https://ncov.moh.gov.vn/.

Nguyen Q.M. et al. (2020) 'Identifying and Assessing the Attractiveness of Public Spaces for the Youth as a Key Factor to Help Establish Social Sustainability-Case Studies from Hanoi' In: Reddy J., Wang C., Luong V., Le A. (eds) ICSCEA 2019. Lecture Notes in Civil Engineering, Vol 80, Springer, Singapore, https://doi.org/I0.1007/978-98|-I5-5I44-4 I2.

Nguyen T.T.P., Nguyen L.H., Le H.T., Vu G.T., Hoang M.T., Nguyen D.N., Le X.T.T., Tran B.X., Nguyen T.T., Pham Q. T., Ta N.T.K., Nguyen Q.T., Latkin C.A., Ho R.C.M. and Ho C.S.H. (2020) 'Perceptions and Attitudes Toward COVID-19-Related National Response Measures of Vietnamese: Implications for Pandemic Prevention and Control', Front. Public Health 8:589053. doi: 10.3389/fpubh.2020.589053. 
Youth Access to Public Space during COVID-19 Pandemic in Hanoi, Vietnam

Pham, T. T. H., Labbé, D., Lachapelle, U., Pelletier, E.(2019) 'Perception of obstacle to park access and park use amongst youth in Hanoi - How cultural and local context matters', Landscape and Urban Planning, No. 189, pp. I56-165.

Sanders, P., Zuiggest, M., Geurs. K.(2015) 'Liveable streets in Hanoi - A principal component analysis', Habitat International, No. 49, pp. 547-558.

Tran, T. H. G.(20I5) 'Old villages and new streets - Stories about public space: Public space system in Trung Hoa - Nhan Chinh new town', Journal of Construction, No. 74, pp. 52-53.

Vietnam News Agency (VNA) (2020) 'The fight against COVID-19 in Vietnam: 100 days of review', Vietnam News Agency <https://www.vietnamplus.vn/cuoc-chien-chong-dich-covid I9-taiviet-nam-100-ngay-nhin-lai/638|40.vnp.

Vietnam-5F Data Team (2020) 'Covid-19 pandemic in Vietnam', https://datastudio.google.com/s/s7-」 5zilzA.

VGP News (2020) 'Infographics: 100-days battle against Covid-19 outbreak', http://news.chinhphu.vn/Home/Infographics-100day-battle-against-Covid 19outbreak/20205/39970.vgp.

Wang $\mathrm{C}$ and Zhao H (2020) 'The Impact of COVID-19 on Anxiety in Chinese University Students', Front. Psychol. I I:I I68. doi: 10.3389/fpsyg.2020.0II68

WHO (2020) 'Coronavirus Disease (COVID-19) Advice For The Public' https://www.who.int/emergencies/diseases/novel-coronavirus-2019/advice-for-public

Yenan Wang, Yu Di, Junjie Ye \& Wenbin Wei (2020) 'Study on the public psychological states and its related factors during the outbreak of coronavirus disease 2019 (COVID-19) in some regions of China', Psychology, Health \& Medicine, Vol 26 (I), Pp. 13 - 22, DOI: I0.1080/I3548506.2020.17468 I 7 . 